\title{
Determining Attenuation of Impulse Noise With an Electrical Equivalent of a Hearing Protection Device
}

\author{
Rafał Młyński \\ Emil Kozłowski
}

Central Institute for Labour Protection - National Research Institute (CIOP-PIB), Poland

Determining the effectiveness of impulse noise attenuation with hearing protection devices (HPDs) is an important part of their selection. Measuring impulse noise parameters under an HPD would involve exposing subjects to impulses with a high peak sound pressure level. This paper presents a computational method of determining impulse noise parameters under the cups of earmuffs. Calculations are done using the transfer function of earmuffs, determined with Shaw's electrical equivalent of an HPD, taking into account the design parameters of earmuffs. The developed method was used for calculations in the presence of impulse noise generated by gunshots. To verify the computational method, the results of these calculations were compared with the results of measurements.

impulse noise noise attenuation hearing protectors transfer function of hearing protection device

\section{INTRODUCTION}

Impulse noise is a hazard in workplaces where objects collide, e.g., in all types of hammers and presses. It is also an inherent phenomenon associated with explosive materials and shots from firearms. Noise generated during explosions and shots is a hazard especially faced by soldiers. This problem applies also to civilian employees in workplaces related to testing and maintaining weapons and testing the properties of explosive materials. Explosives are used in the construction industry and mining, too. The sources of exposure to impulse noise also include shots from firearms outside military use, such as sporting guns, shotguns used for hunting and firearms used by law enforcement, including noise ammunition.

For steady noise, the procedure for selecting hearing protection devices (HPDs) based on esti- mating the effective $A$-weighted sound pressure levels (SPLs) under HPDs [1] has been used for a long time. However, there is no similar solution for the impulse noise hazard. The proposal indicated in informative annex B to Standard No. EN 458:2004 [2] offers certain possibilities, but its result can be an assessment of the effectiveness of HPDs in terms of two parameters only: $A$-weighted equivalent SPL and peak SPL. However, assessing impulse noise hazard according to the hearing damage risk criteria developed for the army requires knowing not only the amplituderelated parameter, but also the duration of the acoustic impulse [3, 4, 5, 6, 7, 8, 9].

Therefore, the computational possibilities of determining the effectiveness of attenuating impulse noise with HPDs are limited. On the other hand, testing attenuation of impulse noise generated by explosions or shots with a high peak

\footnotetext{
This publication was based on the results of a research task carried out within the scope of the second stage of the National Programme "Improvement of safety and working conditions" partly supported in 2011-2013 — within the scope of state services-by the Ministry of Labour and Social Policy. The Central Institute for Labour Protection - National Research Institute is the Programme's main co-ordinator.

Correspondence should be sent to Rafał Młyński, CIOP-PIB, Czerniakowska 16, 00-701 Warszawa, Poland. E-mail: rmlynski@ciop.pl.
} 
SPL would present a tangible risk for the subjects' hearing. This paper presents a computational method of determining impulse noise parameters under the cups of earmuffs, without exposing human subjects. The parameters of noise under the earmuff cup, i.e., noise to which a person wearing earmuffs is exposed, are determined on the basis of the time waveform of impulse noise recorded at the potential location of a subject wearing an HPD.

Calculating parameters characteristic for impulse noise under earmuffs also requires that the transfer function of these earmuffs be known. This paper suggests a method for determining the transfer function of earmuffs based on Shaw's electrical equivalent of an HPD [10], taking into account the design parameters of earmuffs. Brinkmann [11] and Mlynski and Zera [12] calculated the time waveform under earmuffs with the transfer function of earmuffs determined with measurements in the presence of an acoustic signal. The authors of the present work are not aware of anyone using an electrical equivalent of an earmuff.

\section{METHOD}

\subsection{Determining Waveform of Impulse Noise Under HPD}

Knowing the time waveform under a HPD makes it possible to determine the value of any parameter of noise, both related to the signal level and the duration of the impulse. Figure 1 illustrates determining the noise waveform under a HPD.

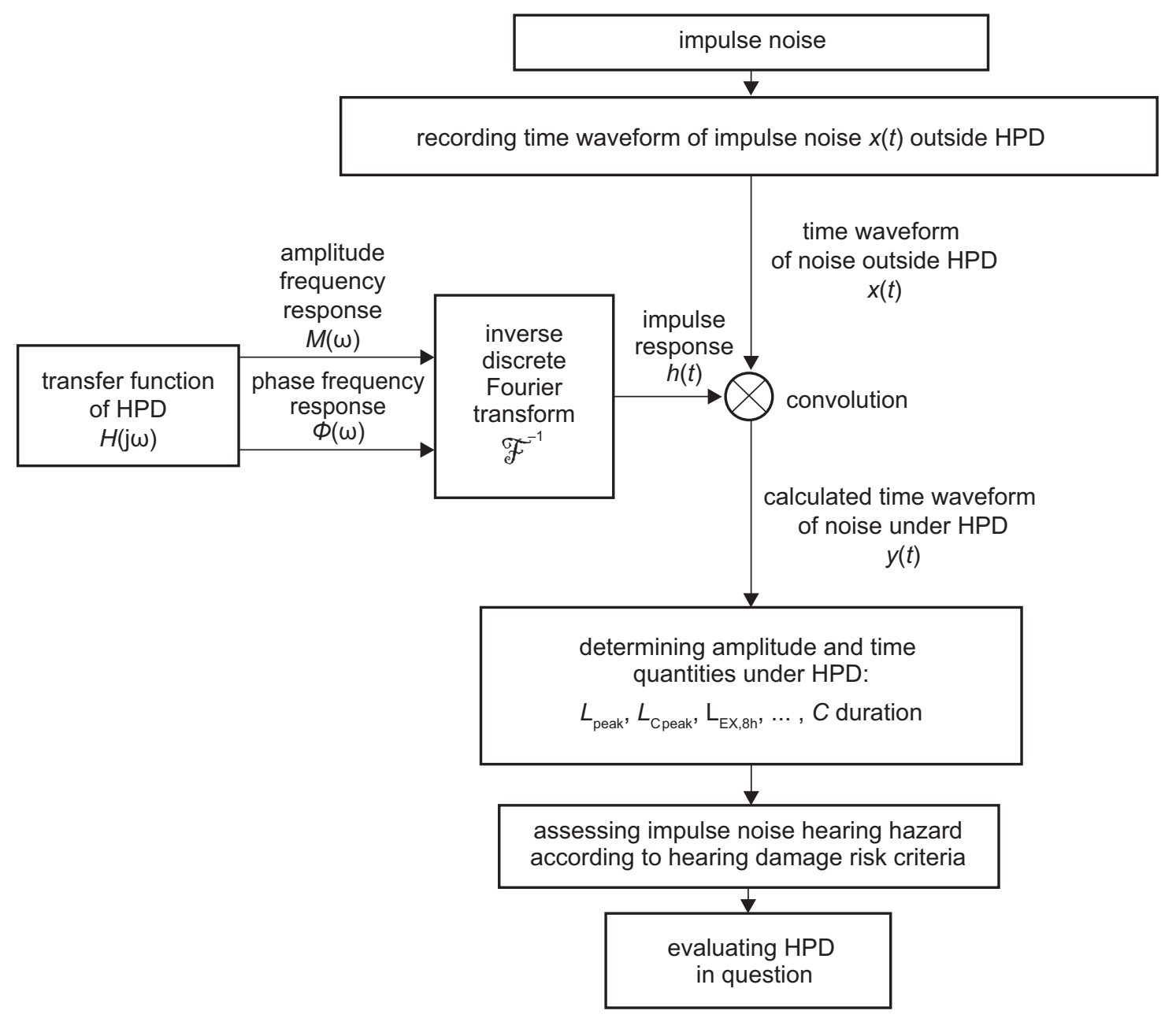

Figure 1. Diagram for computing the time waveform of impulse noise under a hearing protection device (HPD) and the parameters of that noise. Notes. $L_{\text {peak }}=$ peak sound pressure level, $L_{\text {Cpeak }}=C$-weighted peak sound pressure level, $L_{\mathrm{EX}, 8 \mathrm{~h}}=A$-weighted noise exposure level normalized to an 8-h working day (daily noise exposure level). 
Recording the time waveform of impulse noise $x(t)$ occurring at the location of the subject exposed to impulse noise is an indispensable component of the developed method. Calculating the waveform of noise under the HPD consists in performing the operation of convolution of the recorded noise time waveform $x(t)$ and the impulse response $h(t)$ characteristic for the properties of the HPD in question. The impulse response is obtained on the basis of the transfer function of the HPDs through the operation of inverse Fourier transform. The calculated time waveform of impulse noise under the HPD $y(t)$ can be subsequently used to determine any parameters of the noise. The determined parameters are the basis for assessing impulse noise hearing hazard according to specified criteria [3, $4,5,6,13,14]$. Staying within the permissible values of parameters, considered in the hearing damage risk criterion, is reflected in the assessment of suitability of a particular HPD for protection against impulse noise whose time waveform $x(t)$ was recorded at the location of the human subject.

In this paper, the waveform $y(t)$ was used to determine the value of the basic parameter in assessing impulse noise in the workplace, the $C$-weighted peak SPL $\left(L_{\text {Cpeak }}\right)$, defined in regulations on workplaces $[13,14]$. Moreover, the peak SPL $\left(L_{\text {peak }}\right)$ and the $C$-duration of the impulse were determined; they are considered in Pfander's hearing damage risk criterion $[4,5]$.

\subsection{Determining Transfer Function of Earmuff With Shaw's Model}

One way to represent the properties of the earmuff is to use an electrical equivalent, built on the basis of electro-mechano-acoustic analogies in acoustics with the design parameters of the earmuff [15]. Physical models of HPDs were used mainly to describe their properties in the conditions of continuous noise [10, 16, 17, 18]. Only one study discussed the possible modifications indicated in modelling HPDs in the presence of impulse noise [17]; they are qualitative and informative only. Those models were used to obtain the amplitude frequency responses of attenuation of the earmuffs, and the description in question was used to determine both the amplitude and phase frequency response of the earmuff in one case only [18].

Shaw's diagram is the most universal representation of an earmuff [10] (Figure 2). Shaw referred his model to a theoretical, ideal earmuff to obtain amplitude transmission loss characteristics of a vibrating system comprised of a rigid cup and a flexible cushion, testing the influence of specific parameters of the earmuff on its attenuation. The method for determining the parameters of impulse noise used in this paper considers the properties of actual earmuffs. Besides, because determining the time waveform of impulse noise under the earmuff cup requires knowing both the amplitude and the phase frequency response of the earmuff, Shaw's earmuff model was used to determine the transfer function of earmuffs, taking their design parameters into consideration.

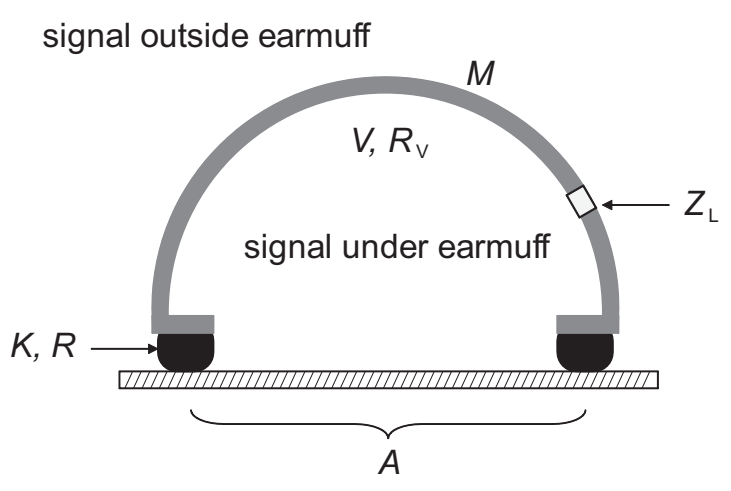

Figure 2. Diagram of an earmuff. Notes. The figure is modelled on Shaw [10]. $M=$ mass of earmuff cup, $V=$ volume enclosed by cup shell, $K=$ stiffness of cushion, $R=$ mechanical resistance of cushion, $A$ = surface area, $Z_{\mathrm{L}}=$ acoustic impedance representing cup leakage.

Representing an earmuff according to the diagram in Figure 2 leads to the electrical diagram in Figure 3, which this paper uses to determine the transfer function of an HPD. The electrical circuit inductance $L_{\mathrm{M}}$, resistance $R_{\mathrm{K}}$ and $R_{\mathrm{V}}$, capacitance $C_{\mathrm{K}}$ and $C_{\mathrm{V}}$ depend on the design parameters of the earmuff, $M, A, R, K$ and $V$, in the way Shaw presented, according to the relationship:

$$
\mathrm{R}_{\mathrm{K}}=\frac{R}{A^{2}}, R_{\mathrm{V}}=\frac{\rho_{0} c}{A}, L_{\mathrm{M}}=\frac{M}{A^{2}}, C_{\mathrm{K}}=\frac{A^{2}}{K}, C_{\mathrm{V}}=\frac{V}{\rho_{0} c^{2}},
$$


where $\rho_{0}=$ medium density; $c=$ speed of sound; $M=$ mass of one earmuff cup; $A=$ contact surface area of the cup cushions; $K=$ stiffness, $R=$ mechanical resistance of the cushion; $V=$ volume enclosed by the shell of one earmuff cup, corrected for $2 \mathrm{~cm}^{3}$, i.e., the volume of an average external ear canal considering the impedance of the eardrum membrane [19].

Shaw did not present any detailed relationships for determining the frequency response nor any method for determining the design parameters of earmuffs, which the present paper does. With the diagram in Figure 3 and assuming perfect sealing by the earmuff cup (acoustic impedance representing cup leakage $\mathrm{Z}_{\mathrm{L}}=\infty$ ), the transfer function of the system $H(j \omega)$ can be presented as Equation 1:

$H(j \omega)=\frac{Y(j \omega)}{X(j \omega)}=\frac{R_{V}-\mathrm{j} \frac{1}{\omega C_{V}}}{R_{V}+R_{K}+j\left(\omega L_{M}-\frac{1}{\omega C_{V}}-\frac{1}{\omega C_{K}}\right)}$,

where $X(j \omega)=$ frequency domain image of the signal occurring outside of the earmuff, $Y(j \omega)=$ frequency domain image of the signal under the earmuff, $\omega=2 \pi f, f=$ signal frequency.

The amplitude frequency response $M(\omega)$ and the phase frequency response $\Phi(\omega)$ necessary to determine the time waveform under the earmuff are determined with Equations 2 and 3, respectively:

$$
\begin{gathered}
M(\omega)=20 \log _{10}|H(j \omega)|, \\
\Phi(\omega)=\operatorname{arctg}[\operatorname{Im}(H(j \omega)) / \operatorname{Re}(H(j \omega))],
\end{gathered}
$$

where $H(j \omega)=$ transfer function of the system, $\operatorname{Re}(H(j \omega))=$ real part of $H(j \omega), \operatorname{Im}(H(j \omega))=$ imaginary part of $H(j \omega)$.

Table 1 presents quantities characterizing the design parameters of 10 earmuffs. The mass, volume and surface area of the cushions were measured directly, with laboratory scales (mass measurement accuracy $0.2 \mathrm{~g}$ ) filling the space of the cup with liquid (volume measurement with the accuracy of $1 \mathrm{~cm}^{3}$ ) and with a cushion pressure force measurement device (Figure 4a) and planimeter Robotron Reiss (German Democratic Republic) 3005 (Figure 4b) to measure the contact surface area of the cushions (surface area measurement accuracy $0.0001 \mathrm{~m}^{2}$ ).

Vibration of the earmuff cups caused by hammer impact results in oscillating waveform of the acoustic pressure under its cup, fading in exponential manner, similar to fading as a result of excitation with impulse noise [8]. This means that in the range of low frequencies (up to $\sim 200 \mathrm{~Hz}$ ), the earmuff excited into vibration behaves like a simple mechanical vibrating single degree-offreedom system (Figure 5) [20]. The mass $M$ of the system in Figure 5 is the mass of the earmuff cup including the mass of the sponge filling and

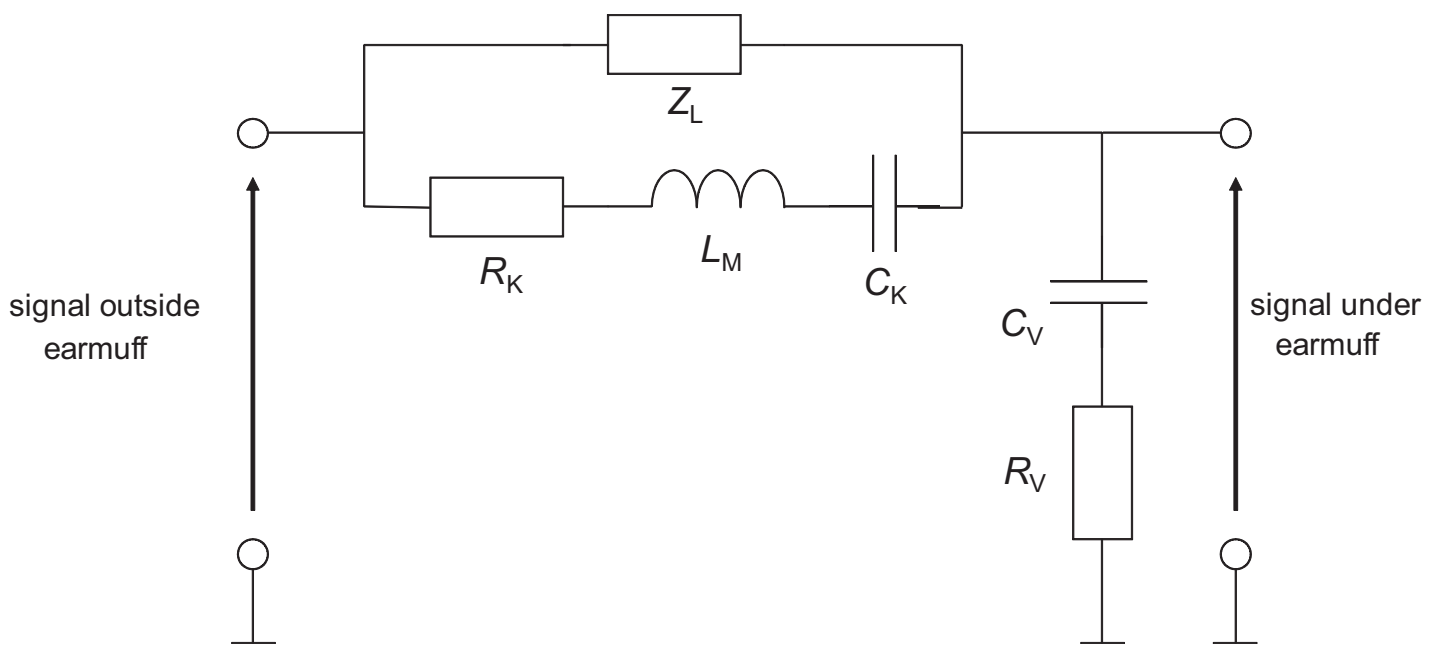

Figure 3. Electrical equivalent of an earmuff. Notes. The diagram is modelled on Shaw [10].

$Z_{\mathrm{L}}=$ acoustic impedance representing cup leakage; $L_{\mathrm{M}}=$ electrical circuit inductance; $R_{\mathrm{K}}, R_{\mathrm{V}}=$ resistance; $C_{\mathrm{K}}, C_{\mathrm{V}}=$ capacitance. 
the cushion. The stiffness $K$ of the system is the spring of the cushions only, because the cup can be considered perfectly rigid. The mechanical resistance $R$ of the system also applies to the earmuff cushion and is related to the friction of the cushions against the base and the cup, the flow of air through gaps and venting holes, and friction of plastic foams in the cushions against the rubber.

The values of the stiffness $K$ and the mechanical resistance $R$ of the cushion were determined with the information about the Q factor and the resonance frequency of the system (Figure 5), obtained on the basis of the curve of the absolute transmissibility according to the relationships pertaining to vibration isolation systems treated as vibrating single degree-of-freedom systems [20]. The curve of the absolute transmissibility of the earmuff system was obtained from the measurement of acceleration of vibration of the earmuff cup put on an acoustic test fixture, and the pressure difference outside and under the earmuff cup, with a sweep-sine acoustic signal. The values of $R$ and $\mathrm{K}$ determined from the curve of the absolute transmissibility are valid for the frequency range covering the area of the resonance peak. The present work assumes that the determined values are representative for the whole frequency range (up to $1 \mathrm{kHz}$ ) of the earmuff under consideration using Shaw's diagram [10].

In the frequency range over $\sim 1 \mathrm{kHz}$, the representation of the earmuff based on the electrical equivalent in Figure 3 cannot be used. At the frequency over $1 \mathrm{kHz}$, the acoustic wavelength becomes comparable to the dimensions of the earmuff cup, so a lumped circuit cannot describe the system [15]. Shaw used Zwislocki's bone conduction limits [21] to represent earmuff attenuation in the frequency range over $1 \mathrm{kHz}$ [10]. Berger, Kieper and Gauger present more recent data on the limitation of attenuation related to bone conduction [22]. Bone conduction, and thus conduction of acoustic energy to the inner ear through the skull, bypassing the external ear canal, eardrum membrane and middle ear ossicles, reduces the attenuation of earmuffs, which block only the airborne path of sound through the external ear canal. Blocking the air path of acoustic energy transmission is bypassed through the

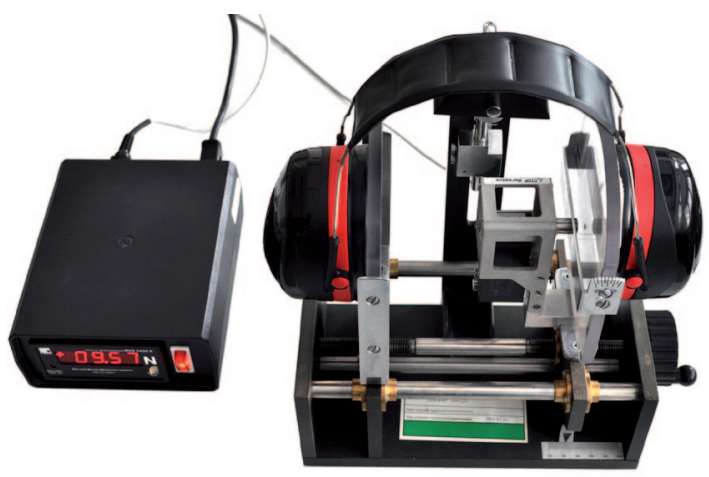

Figure 4a. The SD-30 instrument (Central Mining Institute, GIG; Poland) for determining surface area of earmuff cushions.

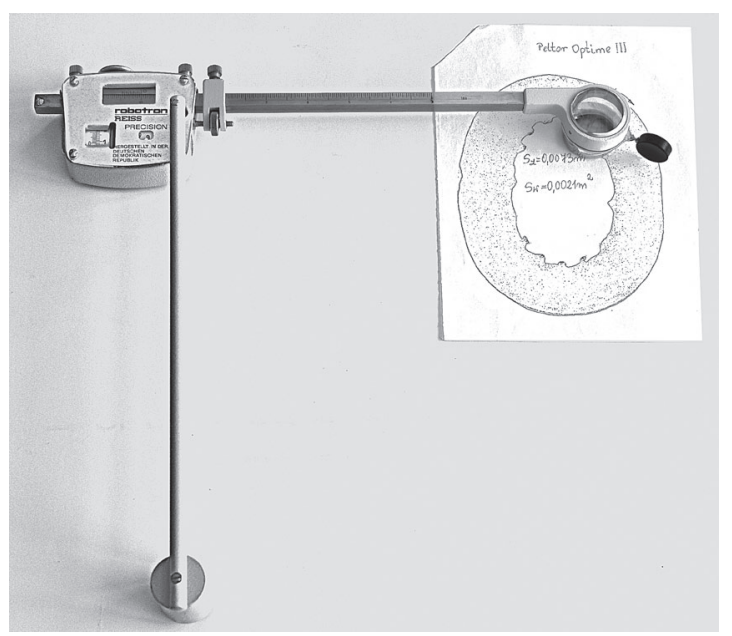

Figure 4b. The Robotron Reiss (German Democratic Republic) 3005 planimeter for measuring contact surface area of earmuff cushions.

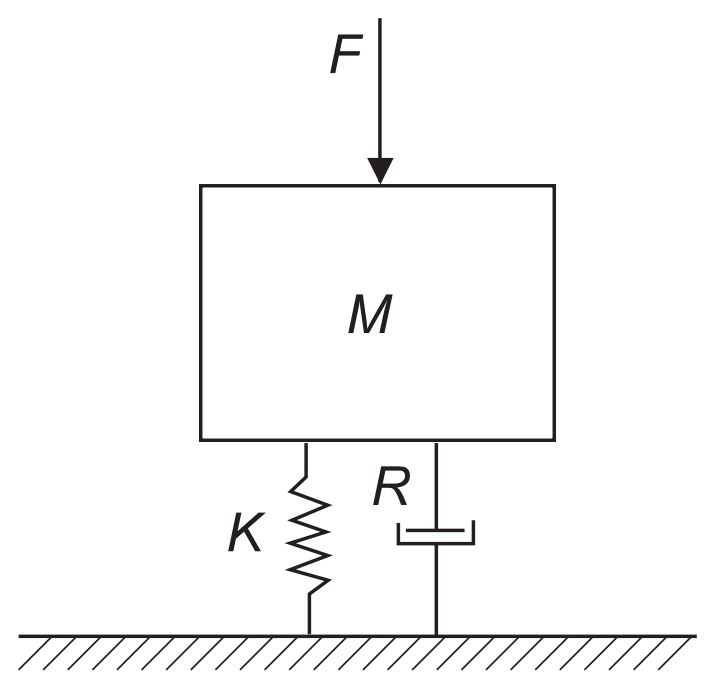

Figure 5. Diagram of a single degree-offreedom vibrating system at excitation force $\boldsymbol{F}$. Notes. $M=$ mass, $R=$ resistance, $K=$ stiffness. 
bones, so the maximum attenuation that can be obtained with HPDs cannot exceed the level of bone conduction, which depending on the frequency is between $\sim-40$ and nearly $-70 \mathrm{~dB}$ relative to air conduction [21, 22]. The use of bone conduction data in the frequency range over $1 \mathrm{kHz}$ in representing the properties of ear protectors is a simplification, because they do not block completely the air path of the sound reaching the eardrum.

Figure 6 shows the amplitude and phase frequency responses of 10 earmuffs obtained from the electrical equivalent of Shaw's model. These responses were obtained with the design parameters of earmuffs in Table 1. At higher frequencies (over $\sim 1 \mathrm{kHz}$ ), the amplitude frequency responses of attenuation (Figure 6a) were adopted as attenuation resulting from bone conduction according to Berger et al. [22], identical for all 10 earmuffs in the present work. Phase frequency responses in the lower frequencies (Figure 6b), where they correspond to the amplitude frequency responses in Figure 6a, are plotted with a continuous line. Because the phase frequency response of bone conduction is not known, the form of phase frequency responses was adopted in the higher frequency range, as if attenuation was not limited by bone conduction. This part of phase frequency responses is plotted with dashed lines.

In the amplitude frequency response waveform, the mechanical resonance of earmuffs is marked in the form of minimum attenuation in the frequency range from 80 to $200 \mathrm{~Hz}$. Above the area of mechanical resonance, the slope of amplitude frequency response obtained in this representation of earmuffs is $\sim 12 \mathrm{~dB} /$ octave, which is in step with the slope of the response of the model earmuff analysed by Shaw [10]. In the range above the mechanical resonance, the attenuation of earmuffs changes by $\sim 15 \mathrm{~dB}$ between the earmuff with the highest and the lowest attenuation, which is in step with the change in the value of the single number rating (SNR) parameter of the earmuffs (Table 1). SNR is used to evaluate sound attenuation by earmuffs, as required by Standard No. EN 352-1:2002 [23] harmonized with Directive 89/686/EEC [24]. The arrangement of amplitude frequency responses corresponding to the value of SNR visible above the mechanical resonance does not occur in the lowest frequency range.

The phase frequency responses are closely related to the amplitude frequency responses (Figure 6b). In the range of mechanical resonance under $200 \mathrm{~Hz}$, the deeper the minimum of the amplitude frequency responses, the greater the slope of the phase frequency response. In the range of high frequencies, the phase frequency responses tend asymptotically towards the $-\pi / 2$ value.

\subsection{Verifying Computational Method}

Verifying the proposed computational method that determines the amplitude and time parameters of impulse noise under the earmuff cup involves

TABLE 1. Design Parameters of Earmuffs and Their Single Number Rating (SNR)

\begin{tabular}{|c|c|c|c|c|c|c|c|}
\hline \multicolumn{2}{|c|}{ Earmuff } & \multirow{2}{*}{$\frac{\text { SNR (dB) }}{21}$} & \multirow{2}{*}{$\frac{M(\mathbf{k g})}{0.0559}$} & \multirow{2}{*}{$\frac{V\left(\mathrm{~cm}^{3}\right)}{128}$} & \multirow{2}{*}{$\frac{A\left(\mathbf{m}^{2}\right)}{0.0041}$} & \multirow{2}{*}{$\frac{K(\boldsymbol{N} / \mathbf{m})}{34481.9}$} & \multirow{2}{*}{$\frac{\boldsymbol{R}(\mathbf{N} \cdot \mathrm{s} / \mathbf{m})}{24.0}$} \\
\hline 1 & Unico Graber Sonico 85 & & & & & & \\
\hline 2 & $3 M 1430$ & 23 & 0.0572 & 112 & 0.0040 & 52947.8 & 26.6 \\
\hline 3 & $3 M 1435$ & 25 & 0.0713 & 128 & 0.0039 & 75764.9 & 38.4 \\
\hline 4 & $3 M 1440$ & 27 & 0.0738 & 136 & 0.0041 & 57615.7 & 31.3 \\
\hline 5 & Peltor Optime I & 27 & 0.0695 & 92 & 0.0042 & 68332.5 & 43.6 \\
\hline 6 & Bilsom Leightning L1 & 30 & 0.0682 & 163 & 0.0040 & 15144.9 & 31.0 \\
\hline 7 & Peltor Optime II & 31 & 0.0853 & 153 & 0.0042 & 39142.4 & 65.2 \\
\hline 8 & Bilsom Leightning L2 & 31 & 0.0814 & 218 & 0.0040 & 25490.2 & 35.3 \\
\hline 9 & Bilsom Leightning L3 & 34 & 0.1213 & 252 & 0.0040 & 22634.2 & 50.2 \\
\hline 10 & Peltor Optime III & 35 & 0.1188 & 186 & 0.0047 & 34637.1 & 108.2 \\
\hline
\end{tabular}

Notes. $M=$ mass of one earmuff cup, $V=$ volume enclosed by the shell of one earmuff cup, $A=$ contact surface area of earmuff cup cushion, $K=$ stiffness of cup cushion, $R=$ mechanical resistance of earmuff cup cushion. 


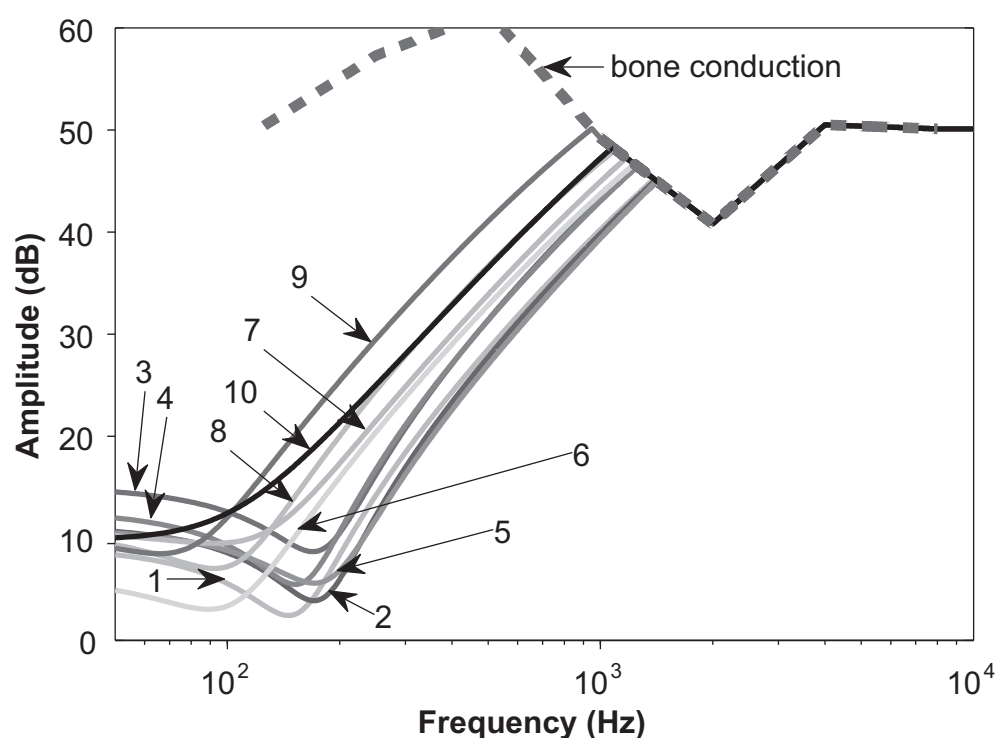

Figure 6a. Amplitude frequency responses of earmuffs and the limit of bone conduction [22]. Notes. 1-10 = earmuffs (see Table 1); continuous lines = amplitude frequency responses of earmuffs, dashed line $=$ bone conduction limits of attenuation of earmuffs.

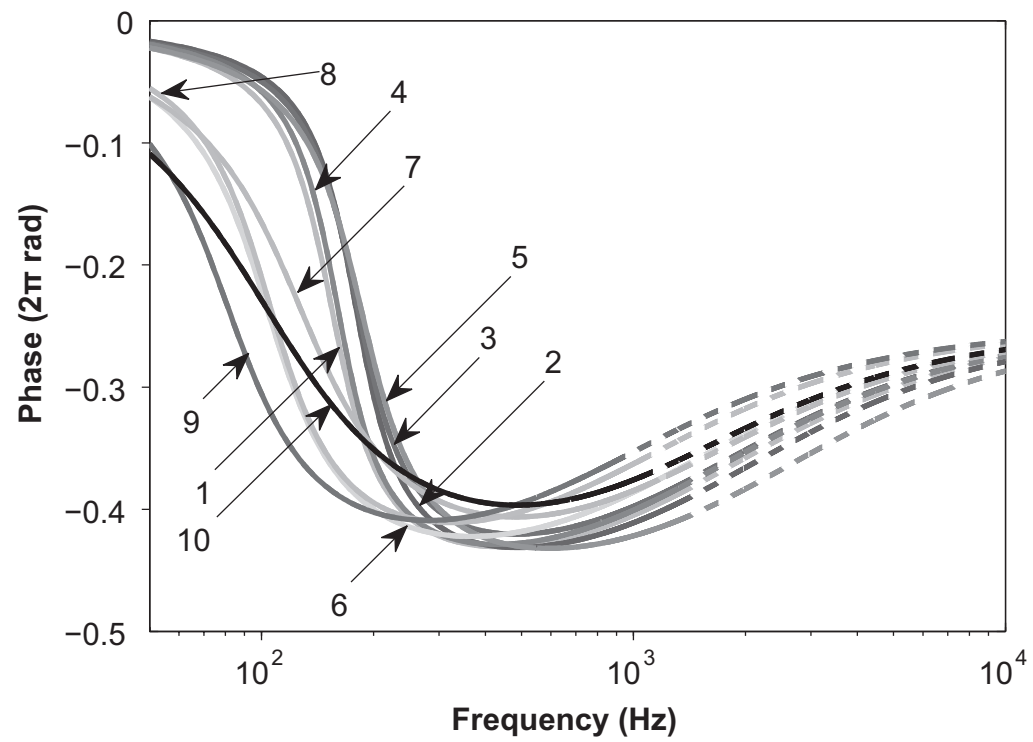

Figure 6b. Phase frequency responses of earmuffs. Notes. 1-10 = earmuffs (see Table 1); continuous lines = phase frequency responses of earmuffs corresponding to amplitude frequency responses in Figure $6 \mathrm{a}$ in the same frequency ranges (up to $\sim 1 \mathrm{kHz}$ ); dashed lines = phase frequency responses of earmuffs, as if attenuation was not limited by bone conduction.

comparing calculated and measured values. To use the computational method, it is necessary to record the sound pressure waveform at the location of the human subject exposed to noise. The presence of the subject is not necessary, though. Verifying the computational method, however, requires that a simultaneous recording of the time waveform of impulse noise under the earmuffs be carried out. The next step determines the parameters pertaining to the amplitude and duration of impulse noise on the basis of the calculated waveform and the waveform recorded under the cup of a specific earmuff. The discrepancies between the computed parameters characterizing the time waveform of impulse noise under the earmuff and their values measured under the earmuff indicate whether the proposed method is suitable for practical applications. 


\section{TESTS AND CALCULATIONS}

The computational method discussed in section 2 was used to determine the parameters of impulse noise under earmuffs during shots from two types of pistols: the Walther P99 (Carl Walther GmbH Sportwaffen, Germany) and the TT-33 (Tula Arsenal, Soviet Union). The measurements of impulse noise took place at a sporting rifle range; the results were verified there, too. Calculations and measurements were performed for 10 earmuffs from different manufacturers with a wide range of values (21-35 dB) of the SNR parameter (Table 1). There were three measurements for each earmuff and for each pistol. Thus, there were 60 sets of measurement results, comprising the sound pressure waveform of the impulse outside and under the earmuff, which was recorded simultaneously.

\subsection{Measurement Setup}

Changes in the sound pressure related to acoustic impulses occurring outside the earmuff were recorded with a Brüel \& Kjær (Denmark) 4941 microphone (1/4"). The waveforms of impulse noise under the cups of tested earmuffs were recorded with an acoustic test fixture so that human subjects were not exposed to values of the peak SPL over $135 \mathrm{~dB}$, i.e., the value established in Polish regulations [14]. The acoustic test fixture complied with the acoustic and mechanical requirements for this type of equipment [25] and was equipped with a Brüel \& Kjær 4192 microphone (1/2"). The fixture was also equipped with a chamber representing the external ear canal and a $2-\mathrm{cm}^{3}$ chamber reflecting the acoustic properties of the middle ear. During the measurements, the acoustic test fixture and the microphone recording the signal waveform outside the HPDs were set $160 \mathrm{~cm}$ from the exit of the pistol barrel, at the position of a shooting instructor. The external microphone was placed $10 \mathrm{~cm}$ from the acoustic test fixture.

\subsection{Measurement Results}

Impulse noise generated by shots from the Walther P99 (Figure 7a) had an average, based on
30 shots, $C$-weighted SPL of $150.5 \mathrm{~dB}$ (SD 0.5). The duration of an impulse, expressed in accordance with the definition of $C$-duration used in the Pfander hearing damage risk criterion, was $0.87 \mathrm{~ms}$ ( $S D$ 0.23). Shots from the TT-33 (Figure $7 b)$ produced acoustic impulses had an average, based on 30 shots, $C$-weighted peak SPL of $149.4 \mathrm{~dB}(S D$ 0.6) and an average $C$-duration of $0.82 \mathrm{~ms}$ ( $S D$ 0.24). The $C$-weighted peak SPL measured under the cups of the tested earmuffs was $108.0-127.7 \mathrm{~dB}, C$-duration was $2.3-12.1 \mathrm{~ms}$. Figure 8 illustrates the effectiveness of the 10 tested earmuffs in reducing the $C$-weighted peak SPL. There was an overall trend of attenuation of the $C$-weighted peak SPL increasing with increasing SNR of the earmuff. This relationship was not strictly monotonic and the attenuation of the $C$-weighted peak SPL cannot be strictly related to the value of SNR. It has been also verified that mean sound attenuation or assumed protection values at 63,125 and $250 \mathrm{~Hz}$, the $H, M$ and $L$ values [1], do not show better monotonic correlation with the attenuation of the $C$-weighted peak SPL than SNR.

\subsection{Discrepancies Between Computational Method and Measurements}

The transfer function of earmuffs obtained from Shaw's electrical equivalent [10] (section 2.2) was used to calculate the time waveforms of the sound pressure of the signal under the earmuffs as a response to the time waveforms of the sound pressure of impulses recorded outside the earmuffs (section 2.1). The parameters characterizing the waveforms were determined on the basis of the calculated time waveforms of the signal under the earmuffs.

The usefulness of the presented computational method for estimating the effectiveness of earmuffs in the presence of impulse noise was checked by comparing the results of measurements carried out under earmuff cups with the waveforms resulting from the computational method. Figure 9a is an example of a computed time waveform of the signal under the earmuff, whereas Figure $9 \mathrm{~b}$ is a comparable recorded waveform. 

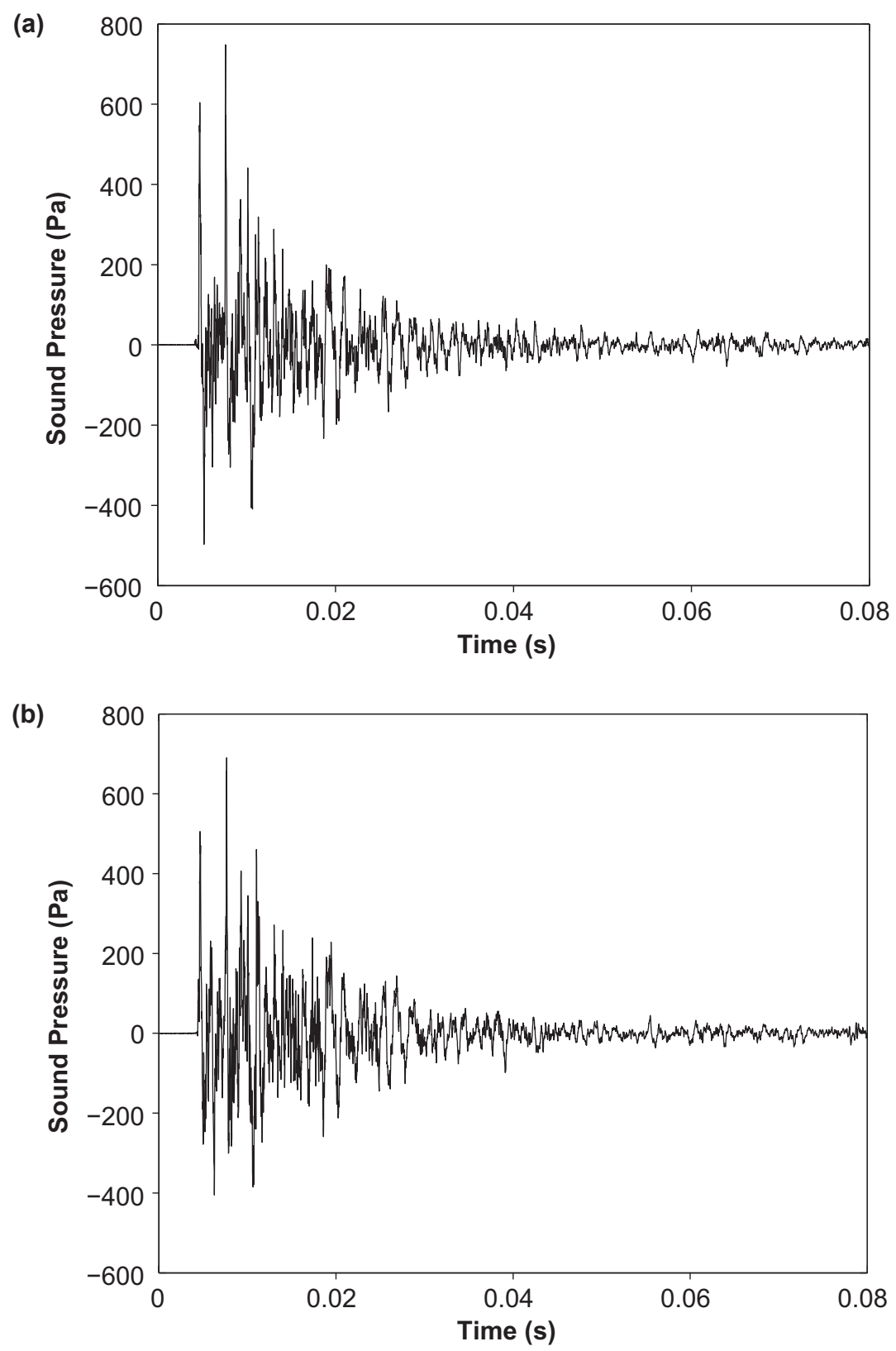

Figure 7. Sample acoustic impulse waveform generated by a pistol shot: (a) the Walther P99 (Carl Walther GmbH Sportwaffen, Germany); (b) the TT-33 (Tula Arsenal, Soviet Union).

The discrepancy between the calculation and measurement of each parameter related to the level of sound, $L_{\text {Cpeak }}$ and $L_{\text {peak }}$, was determined as an absolute difference of the measured values and values from the calculated waveform. $\Delta L_{\text {Cpeak }}$ and $\Delta L_{\text {peak }}$ designate the discrepancy in $L_{\text {Cpeak }}$ and $L_{\text {peak }}$, respectively. The discrepancy in $C$-duration ( $\Delta C$-duration) was determined as a relationship between calculated and measured $C$-duration. The $C$-duration of the calculated impulse was longer in each case than the $C$-dura- tion of the measured impulse, so all discrepancy values for the $C$-duration were greater than one. Figures 10-12 show the discrepancies in $\Delta L_{\text {Cpeak }}$, $\Delta L_{\text {peak }}$ and $\Delta C$-duration, respectively. Each discrepancy value (each bar representing the results) in those figures was determined by averaging the results of three comparisons of calculations and measurements. These figures also indicate the value of standard errors related to the values of discrepancies. 


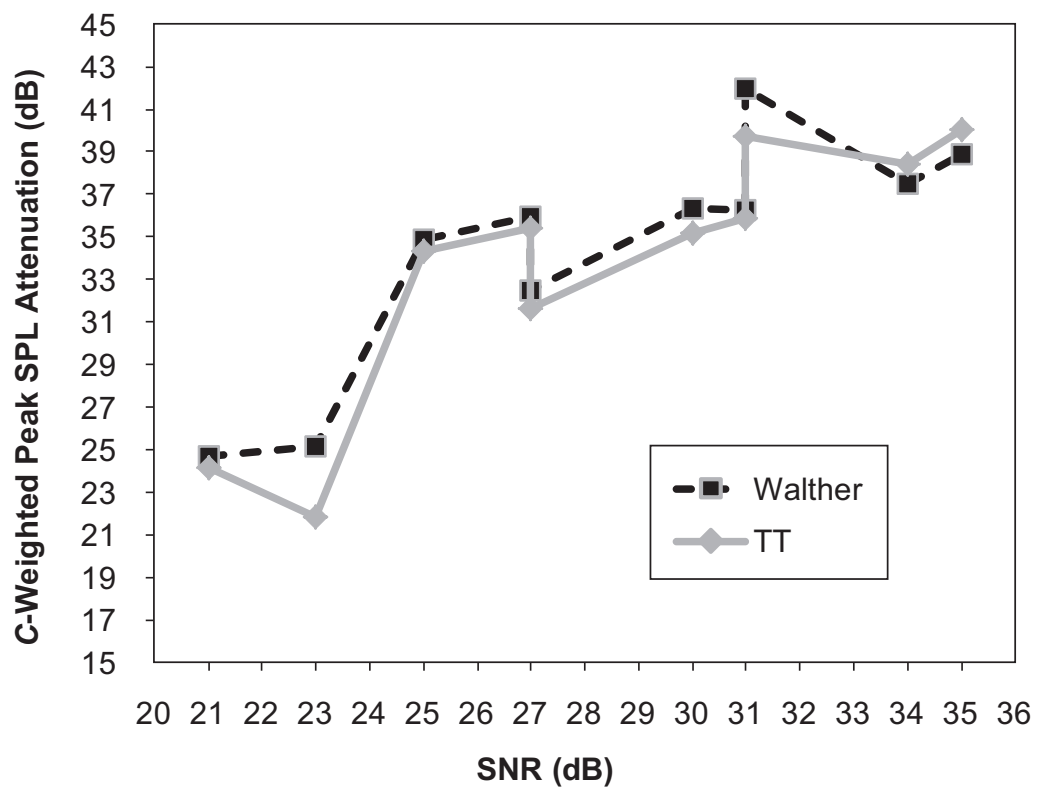

Figure 8. Measured attenuation of $C$-weighted peak sound pressure level (SPL) for earmuffs as a function of single number rating (SNR) of each earmuff, for shots from the Walther P99 (Carl Walther GmbH Sportwaffen, Germany) and the TT-33 (Tula Arsenal, Soviet Union). Notes. $L_{\text {Cpeak }}=C$-weighted peak sound pressure level.

It should be noted that the values of $\Delta L_{\mathrm{C} \text { peak }}$ (Figure 10) and $\Delta L_{\text {peak }}$ (Figure 11) for each earmuff are similar. For these two parameters, for 7 out of the 10 tested earmuffs, the calculated value of the $C$-weighted peak SPL deviates from the measured value by no more than $3.2 \mathrm{~dB}$, while for the 3 other earmuffs, it is in the range of $5.8-7.6 \mathrm{~dB}$. The $\Delta L_{\text {Cpeak }}$ and $\Delta L_{\text {peak }}$ discrepancies of $\sim 3 \mathrm{~dB}$ are low. The discrepancies of $\sim 3 \mathrm{~dB}$ are comparable to the distribution of $L_{\mathrm{C} \text { peak }}$ and $L_{\text {peak }}$ for impulses generated in the same conditions. For example, the difference between the lowest and highest values of the $C$-weighted peak SPL of impulse noise (30 shots) produced by the TT-33 was $2.6 \mathrm{~dB}$, and the difference between the minimum and maximum values of the peak SPL produced by the Walther P99 was $3.0 \mathrm{~dB}$. The higher values of $\Delta L_{\text {Cpeak }}$ and $\Delta L_{\text {peak }}$ occurred for the two lightest earmuffs (Unico Graber Sonico 85 and 3M 1430) and for the Bilsom Leightning L3 earmuff with the highest mass. The manufacturer of the Bilsom Leightning L3 earmuff installed a metal weight inside the cup.

The relationship between the longest and the shortest impulse duration, $C$-duration, for acoustic impulses generated in the same conditions by the Walther P99 and the TT-33 was 2.9 and 3.4, respectively. That means the approximately threefold ratio between computed and measured $C$-duration under the same cup, i.e., a threefold discrepancy of $C$-duration, is low. $\Delta C$-duration was not greater than 2.8 for all earmuffs in the presence of shots from the Walther P99. For shots from the TT-33, the ratio of calculated and measured $C$-duration exceeded 3 for all three of the tested Bilsom earmuffs. The Bilsom Leightning L3 earmuffs had the largest discrepancy of 5.9; they also had a greater discrepancy of $L_{\text {Cpeak }}$ and $L_{\text {peak }}$. All three Bilsom earmuffs had the lowest stiffness among the 10 earmuffs.

\section{DISCUSSION AND CONCLUSIONS}

The transfer function determined from Shaw's electrical equivalent [10] describes the properties of HPDs with a high resolution as a function of frequency, allowing it to be used in calculating the time waveform of impulse noise under HPDs. This is not possible with the sound attenuation values measured in accordance with Standard No. ISO 4869-1:1990 [26], provided by default in the 
(a)

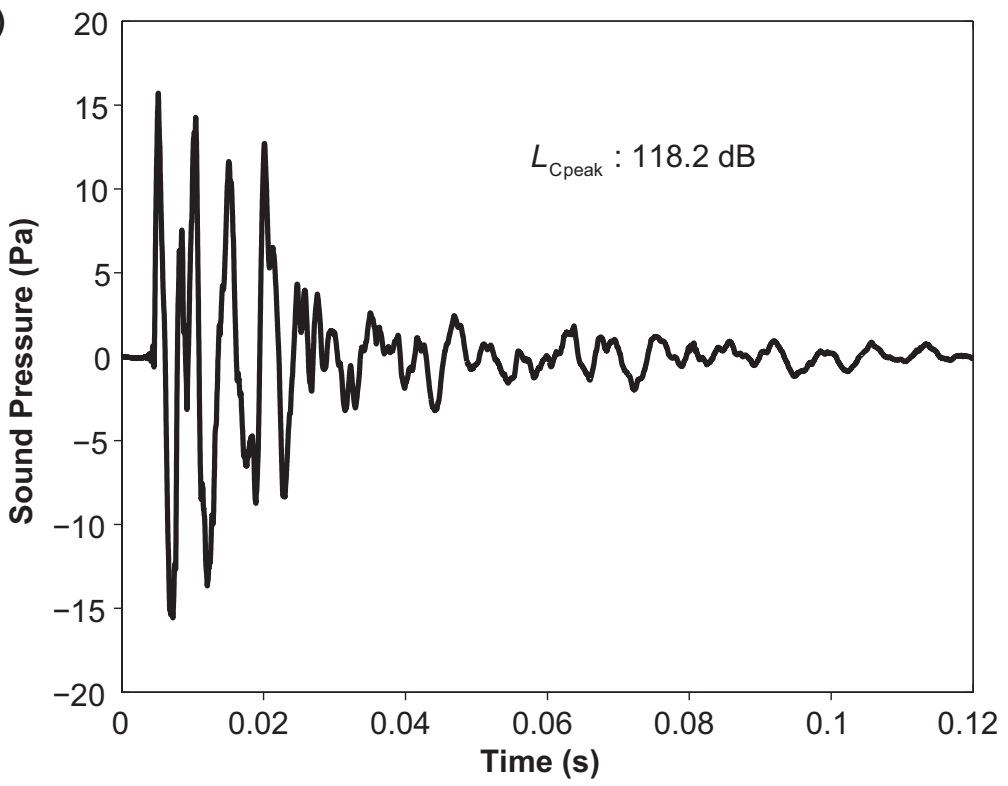

(b)

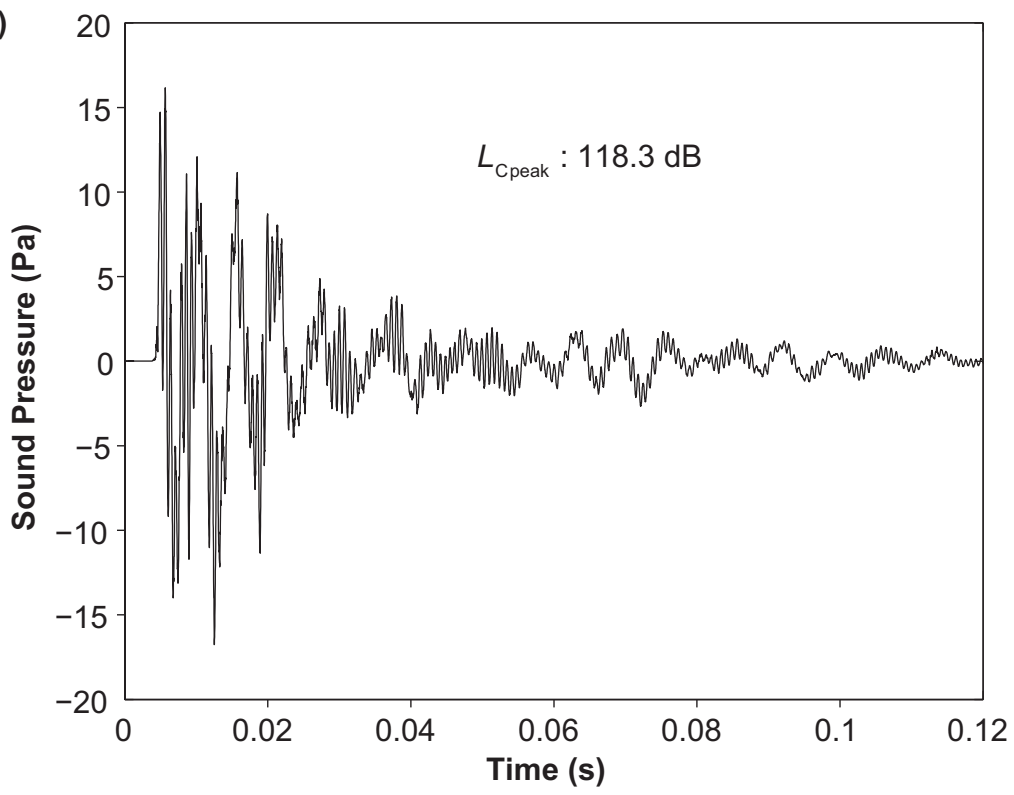

Figure 9. Sample time waveform of the signal under the cup of the Peltor Optime I earmuff: (a) computed, (b) recorded. Notes. $L_{C \text { peak }}=C$-weighted peak sound pressure level.

HPD user manuals, which is defined only in seven one-third-octave frequency bands. It should be noted that, on the basis of the calculated time waveform of impulse noise under HPDs, it is possible to determine quantities related to the signal level, impulse duration and other quantities used to characterize impulse noise, e.g., spectral analysis or specific measures of impulsiveness of the signal (kurtosis).

The calculations in which the transfer function is determined on the basis of Shaw's electrical equivalent of an earmuff, as it was used in the classical model developed for continuous noise, make it possible to consider the quantities representing the design parameters of the earmuff: the mass of cups, their volume, contact surface, stiffness and mechanical resistance of cushions. Determining the transfer function with this method, however, involves the need to measure the design parameters of earmuffs.

The determined values of design parameters of earmuffs made it possible to calculate the param- 


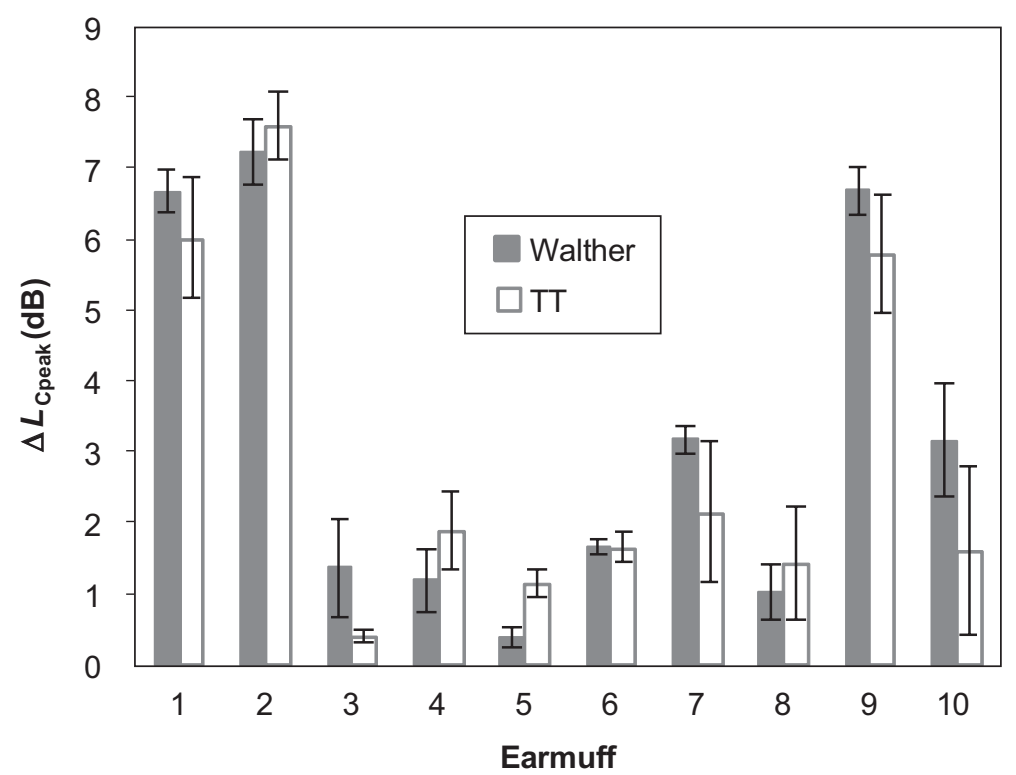

Figure 10. Discrepancy between computed and measured values of $\boldsymbol{C}$-weighted peak sound pressure level (SPL) for earmuffs, for shots from the Walther P99 (Carl Walther GmbH Sportwaffen, Germany) and the TT-33 (Tula Arsenal, Soviet Union). Notes. $\Delta L_{\text {Cpeak }}=$ absolute difference between calculated and measured C-weighted peak SPL. Each bar represents the average result obtained on the basis of 3 comparisons of calculations and measurements. Whiskers represent standard error.

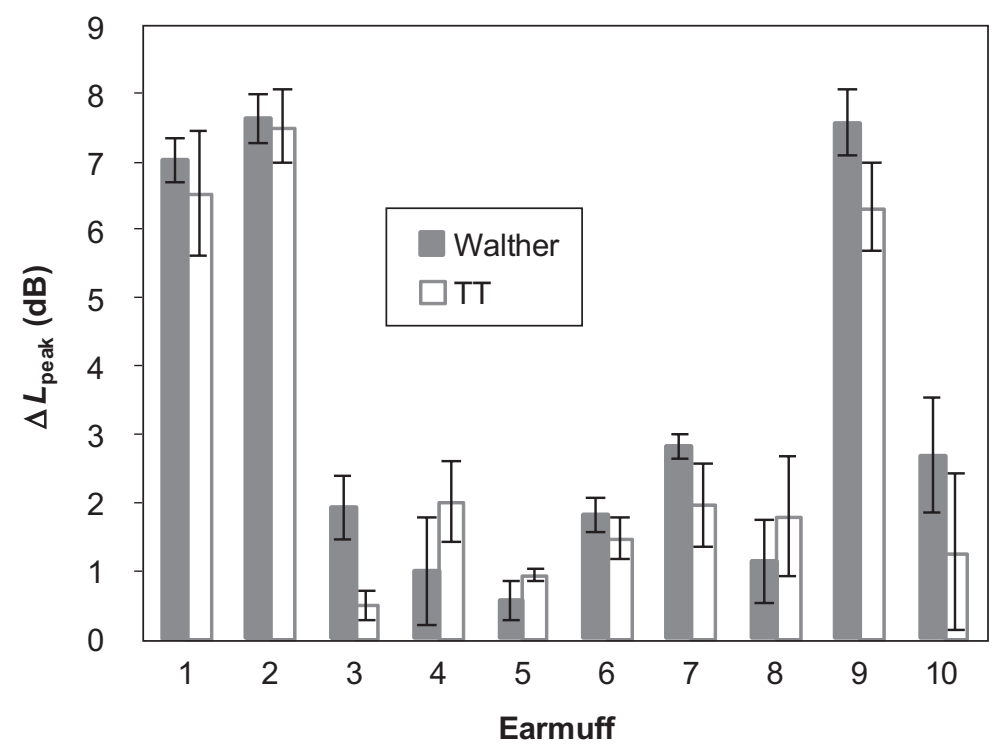

Figure 11. Discrepancy between computed and measured values of peak sound pressure level (SPL) for earmuffs, for shots from the Walther P99 (Carl Walther GmbH Sportwaffen, Germany) and the TT-33 (Tula Arsenal, Soviet Union). Notes. $\Delta L_{\text {peak }}=$ absolute difference between calculated and measured values of peak SPL. Each bar represents the average result obtained on the basis of 3 comparisons of calculations and measurements. Whiskers represent standard error.

eters related to signal amplitude and duration of acoustic impulse under the earmuffs. It was then possible to compare the calculated and measured values of impulse noise under the earmuff. The discrepancy of the calculated and measured values of the $C$-weighted peak SPL and the peak SPL for 7 out of the 10 earmuffs was $\sim 3 \mathrm{~dB}$ and was fully acceptable, because it was comparable to the range of values of these parameters characteristic for impulse noise generated in the same conditions. Greater discrepancies of parameters associated with the amplitude are to be expected for earmuffs with extremely small and large mass. The relationship between the calculated 


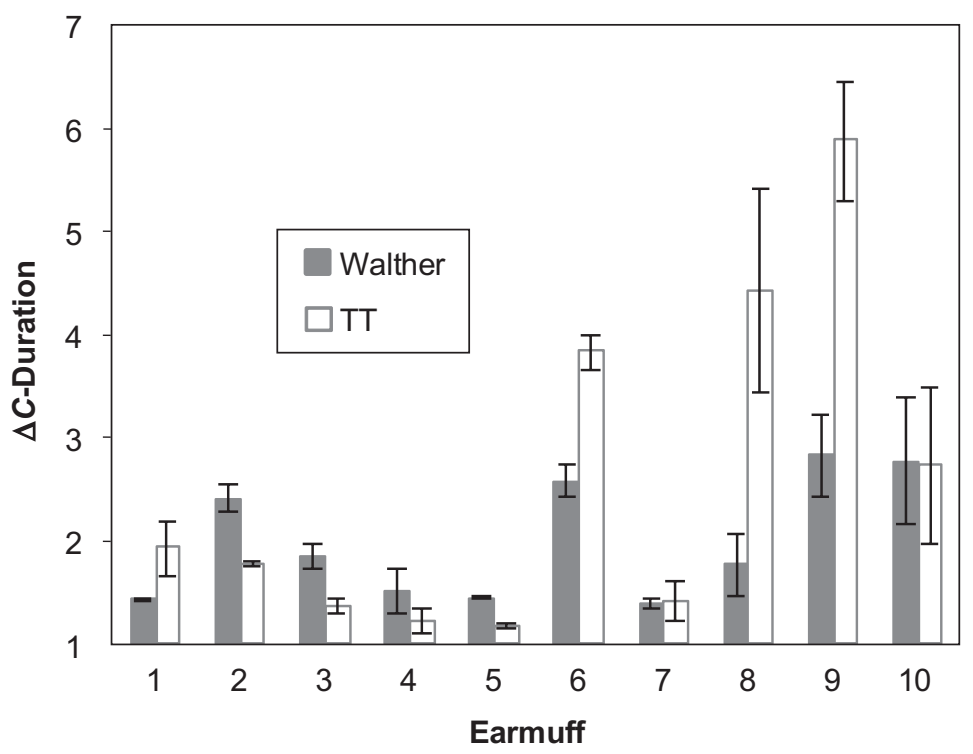

Figure 12. Discrepancy between computed and measured values of $\boldsymbol{C}$-duration for earmuffs, for shots from the Walther P99 (Carl Walther GmbH Sportwaffen, Germany) and the TT-33 (Tula Arsenal, Soviet Union). Notes. $\Delta C$-duration = relationship between calculated and measured $C$-duration. Each bar represents the average result obtained on the basis of 3 comparisons of calculations and measurements. Whiskers represent standard error.

and measured duration of the impulse under the earmuff cup in most cases is no more than threefold, which is acceptable considering the range of variability of duration of impulses in a real system. As regards determining $C$-duration of the impulse under the earmuff cup, greater discrepancy is possible for earmuffs with extremely low value of the stiffness of cushions.

The presented values of discrepancies between calculations and measurements should be considered especially when the parameter values are near the limit values of the corresponding criteria. For example, awareness of the deviation of the calculation result from the measured value is necessary when the $C$-weighted peak SPL is close to $135 \mathrm{~dB}$, which is the highest admissible value of this parameter in Poland [14]. Similarly, information about possible discrepancies of values is significant when the calculated peak SPL and $C$-duration of the impulse are near the boundary line of the Pfander hearing damage risk criterion.

\section{REFERENCES}

1. International Organization for Standardization (ISO). Acoustics - hearing protectors-part 2: estimation of effective
A-weighted sound pressure levels when hearing protectors are worn (Standard No. ISO 4869-2:1994). Geneva, Switzerland: ISO; 1994.

2. European Committee for Standardization (CEN). Hearing protectors-recommendations for selection, use, care and maintenance-guidance document (Standard No. EN 458:2004). Brussels, Belgium: CEN; 2004.

3. Ward WD, editor. Proposed damage-risk criterion for impulse noise (gunfire).

Report of Working Group 57. [Washington, DC, USA]: National Academy of Sciences - National Research Council, Committee on Hearing, Bioacoustics, and Biomechanics (CHABA); 1968.

4. Pfander F. Damage risk criteria with and without ear protection for impulse noise with high intensities regarding ear, larynx and lungs. Scand Audiol Suppl. 1982;16: 41-8.

5. Pfander F, editor. Das Schalltrauma [Acoustic trauma] (Schriftenreihe Präventivmedizin [Preventive medicine series] PM 1). Bonn, Germany: Ministry of Defence; 1994.

6. Smoorenburg GF. Damage risk criteria for impulse noise. In: Hamernik RP, 
Henderson D. Salvi R, editors. New perspectives on noise. New York, NY, USA: Raven Press; 1982. p. 471-90.

7. Toppila E, Starck J. The attenuation of hearing protectors against high-level shooting impulses. Archives of Acoustics. 2004;29(2):275-82.

8. Zera J, Mlynski R. Attenuation of highlevel impulses by earmuffs. Journal of the Acoustical Society of America. 2007; 122(4):2082-96.

9. Lwow F, Józków P, Mędraś M. International Journal of Occupational Safety and Ergonomics (JOSE). 2011; 17(1):69-77. Retrieved March 28, 2012, from: http://www.ciop.pl/41814.

10. Shaw EAG. Hearing protector design concepts and performance limitations. In: Alberti PW, editor. Personal Hearing Protection in Industry. International Symposium on Personal Hearing Protection. New York, NY, USA: Raven Press; 1980. p. 51-68.

11. Brinkmann H. Effectiveness of ear protection against impulse noise. Scand Audiol Suppl. 1982;16:23-39.

12. Mlynski R, Zera J. Prediction of impulsive noise waveform under an earmuff worn by a real user [abstract]. Journal of the Acoustical Society of America. 2008;123(5):3529.

13. Directive 2003/10/EC of the European Parliament and of the Council of 6 February 2003 on the minimum health and safety requirements regarding the exposure of workers to the risks arising from physical agents (noise). OJ. 2003;L42:38-44. Retrieved March 28, 2012, from: http://eurlex.europa.eu/LexUriServ/LexUriServ.do?ur i=OJ:L:2003:042:0038:0044:EN:PDF.

14. Rozporządzenie Ministra Pracy i Polityki Społecznej z dnia 29 listopada 2002 r. w sprawie najwyższych dopuszczalnych stężeń i natężeń czynników szkodliwych dla zdrowia w środowisku pracy [Regulation of the Minister of Labor and Social Policy of 29 November 2002 on the maximum admissible concentrations and intensities of factors harmful to health in the workplace]. Dz U. 2002;(217):item 1833; amended by Dz U. 2005;(212):item 1769; Dz U. 2007;(161):item 1142; Dz U. 2009;(105):item 873; Dz U. 2010;(141): item 950. In Polish. Retrieved March 28, 2012, from: http://www.mpips.gov.pl/ userfiles/File/Prawo/Warunki\%20 pracy/2011/4.\%20NDS\%20zm_01.11.pdf.

15. Beranek LL. Acoustics. New York, NY, USA: American Institute of Physics; 1996.

16. Zwislocki J. Design and testing of earmuffs. Journal of the Acoustical Society of America. 1955;27(6):1154-63.

17. Buck K. Performance of hearing protectors in impulse noise. In: Damage risk from impulse noise (RTO Lecture Series 219). Neuilly-Sur-Seine, France: North Atlantic Treaty Organization (NATO), Research and Technology Organization (RTO); 2000. p. 3-10. Retrieved March 28, 2012, from: http://ftp.rta.nato.int/public// PubFulltext/RTO/EN/RTO-EN-011///EN011-\$\$ALL.PDF.

18. Pauroablly MR, Pan J. The mechanisms of passive ear defenders. Applied Acoustics. 2000;60(3):293-311.

19. Shaw EAG. The external ear. In: Keidel WD, Neff WD, editors. Handbook of sensory physiology. Berlin: Springer; 1974. vol. V/1, p. 455-90.

20. Harris CM, Piersol AG. Harris' shock and vibration handbook. 5th ed. New York, NY, USA: McGraw-Hill; 2002.

21. Zwislocki J. In serch of the bone conduction threshold in a free sound field. Journal of the Acoustical Society of America. 1957;29(7):795-804.

22. Berger EH, Kieper RW, Gauger D. Hearing protection: surpassing the limits to attenuation imposed by the bone-conduction pathways. Journal of the Acoustical Society of America. 2003;114(4):1955-67.

23. European Committee for Standardization (CEN). Hearing protectors-safety requirements and testing - part 1 - earmuffs. (Standard No. EN 352-1:2002). Brussels. Belgium: CEN; 2002.

24. Council Directive of 21 December 1989 on the approximation of the laws of the Member States relating to personal protective equipment (89/686/EEC). OJ. 1989;L399:1-31. Retrieved March 28, 2012, from: http://eur-lex.europa.eu/ LexUriServ/LexUriServ.do?uri=CONSLE G:1989L0686:20031120:EN:PDF. 
25. International Organization for Standardization (ISO). Acoustics-hearing protectors-part 3: measurement of insertion loss of ear-muff type protectors using an acoustic test fixture (Standard No. ISO 4869-3:2007). Geneva, Switzerland: ISO; 2007.
26. International Organization for Standardization (ISO). Acoustics-hearing protectors-part 1: subjective method for the measurement of sound attenuation (Standard No. ISO 4869-1:1990). Geneva, Switzerland: ISO; 1990. 